\title{
Investigation of the Aerosol Indirect Effect at the Southern Great Plains Using Ground-Based Remote Sensors and Modeling
}

ER63324-1018702-0007414

\author{
PI: Graham Feingold, NOAA
}

\section{Final Project Report}

\begin{abstract}
Over the past years we demonstrated first measurements of the aerosol indirect effect using ground-based remote sensors at a continental US site. The response of a cloud to changes in the aerosol loading is quantified in terms of a relative change in cloud drop effective radius for a relative change in aerosol extinction under conditions of equivalent cloud liquid water path. This is done in a single column of air at a temporal resolution of $20 \mathrm{~s}$ (spatial resolution of $\sim 100 \mathrm{~m}$ ). Cloud drop effective radius is derived from a cloud radar, microwave radiometer, and where applicable, a surface measurement of the accumulation mode aerosol concentration. Aerosol extinction is measured below cloud base by a Raman lidar. The method differs from satellite remote-sensing measurements of the indirect effect in that it samples at scales appropriate to cloud drop activation, i.e., the large eddy scale and is therefore process-based, rather than statistically-based. The main achievements are summarized as follows:

- The method was demonstrated for non-precipitating ice-free clouds at the Southern Great Plains (SGP) Atmospheric Radiation Measurement (ARM) site;

- A modeling analysis of the measurement methodology was undertaken to determine measurement requirements, and the suitability of different CCN proxies;

- We compared five different methods of drop effective radius retrieval for a cloud with extensive cover on May 172003 during the IOP;

- We presented a general methodology for deriving a best estimate of $r_{e}$ from instruments with disparate sampling volumes, footprints and spatial resolutions;

- We compared the first aerosol indirect effect based on different $r_{e}$ retrievals and different proxies for $\mathrm{CCN}$;

- We applied a lidar retrieval method to measure aerosol hygroscopic growth
\end{abstract}

\section{Introduction}

The aerosol indirect effect, usually attributed to Twomey (1977), hypothesizes that increased concentrations of atmospheric aerosol will result in higher concentrations of cloud condensation nuclei (CCN) and increased cloud droplet concentrations. In its original form Twomey clearly stated that the hypothesis applies to clouds of equal liquid water content. Since then a plethora of observational and modeling efforts have addressed 
the indirect effect in a manner that sometimes deviates from the original hypothesis. Usage of the term indirect effect often includes the effect of aerosol on the cloud system (loosely defined as clouds embedded in a dynamical atmosphere) together with associated feedbacks. The general problem of aerosol-cloud interactions encompasses myriad microphysical, dynamical and even chemical processes (e.g., Feingold and Kreidenweis, 2002) that are closely intertwined. Albrecht (1989) suggested that increasing the number of CCN suppresses precipitation and results in more reflective clouds both because droplets are smaller, and because a larger liquid water path is maintained. Conversely, Jiang et al. (2002) showed that elevated polluted layers entrained into clouds may generate dynamic feedbacks that counter the expected increase in cloud albedo. The possibility that both positive and negative feedbacks may exist is indicative of the complexity of the system.

In-situ, airborne observations have played a central role in aerosol-cloud studies (e.g., Brenguier et al., 2000). Using stacked aircraft, sub-cloud aerosol properties (size, composition, CCN spectra) can be sampled simultaneously with in-cloud drop size distributions and updraft velocity so that the relationship between aerosol properties and cloud drop size can be inferred. These detailed measurements address the fundamental aspects of aerosol and cloud microphysics that are necessary to advance our understanding. Unfortunately aircraft campaigns are costly, labor-intensive and not suited to long-term monitoring purposes. Satellite remote sensing plays an important role in monitoring the indirect effect at global scales. Satellites typically measure the effect of aerosol (as represented by optical thickness or other aerosol indices) in cloud-free regions, on the mean drop size or reflectance in adjacent cloudy regions (e.g., Kaufman and Nakajima, 1993; Han et al., 1998 Wetzel and Stowe 1999; Rosenfeld, 2000; Schwartz et al., 2001; Breon et al., 2003). Because these measurements are based on passive radiometery, range-resolved measurements are not possible. In some studies cloud liquid water path is not considered which obscures the indirect effect in its original (Twomey) form (Schwartz et al., 2002); cloud droplets may be smaller because the cloud has less water, and therefore less potential to grow large drops, or the cloud may indeed have smaller drops because there are more condensation sites for the same amount of water.

The current work uses ground-based remote sensors to address the indirect effect in the form proposed by Twomey, namely it looks at clouds of similar liquid water path. It quantifies the change in cloud drop size (retrieved using a cloud radar and microwave radiometer; Frisch et al, 1995) in response to a change in aerosol amount (represented by sub-cloud Raman lidar aerosol extinction). The simultaneous measurement of cloud liquid water path (microwave radiometer) allows this response to be placed within the context of macroscopic changes in the cloud. It does not attempt to trace the various feedback mechanisms that might occur in the dynamical aerosol-cloud system. By considering clouds of similar LWP we in no way imply that LWP is a constant. Rather it is our intent to isolate the aerosol-cloud interaction aspects of the problem from those related to macroscale, dynamic, and thermodynamic processes, as well as feedbacks. This simplification is desirable because there are fundamental aspects of aerosol-cloud interaction that are not well understood. 
The high temporal resolution of the measurements ( $20 \mathrm{~s}$ ) enables us to measure the response of the cloud at scales appropriate to cloud droplet activation. An illustration of the approach is given in Figure 1. Vertical forcing generates cloud with a liquid water path LWP. The aerosol, and in particular the CCN, determine the number of cloud droplets, their size distribution n(r), and the droplet effective radius.

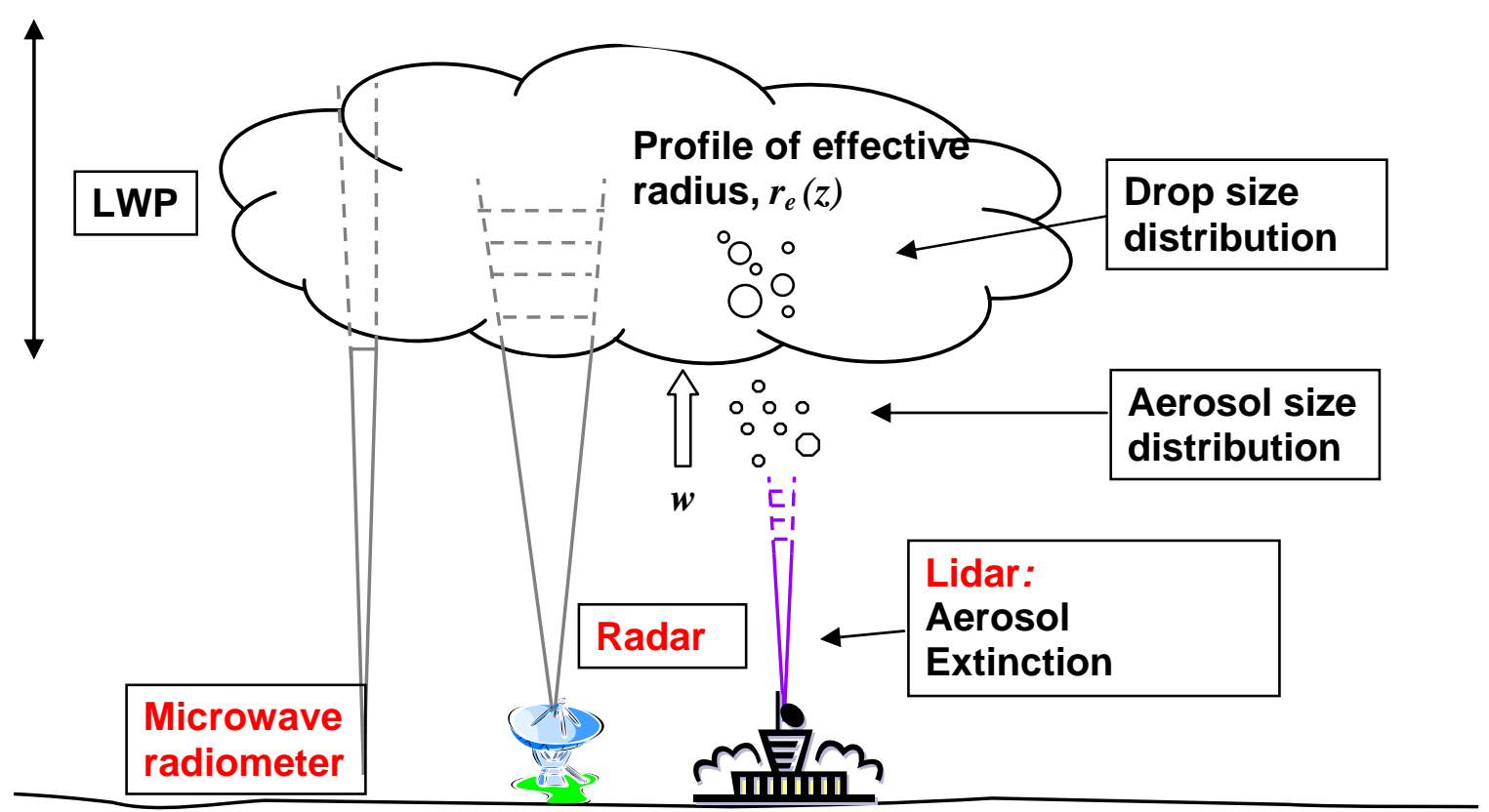

Figure 1: Schematic of measurement methodology

We avail ourselves of a longterm data set acquired at the Southern Great Plains (SGP) Atmospheric Radiation Measurement (ARM) site in Oklahoma, USA -- a rural, continental site which is relatively clean compared to heavy industrial and biomass burning regions.The retrieval is applied to non-precipitating, ice-free clouds in adherence to Twomey's hypothesis. Precipitation is avoided because the microwave radiometer produces spuriously high LWPs during precipitation, and because the drop effective radius (ratio of third to second moments of the drop size distribution) is ill-defined once precipitation ensues. During the summer months contamination of radar reflectivity by insects exacerbates retrieval of cloud microphysics. Therefore analysis is restricted to the spring and fall, when insect activity is low.

\section{Results}

Results pertaining to the main points highlighted in the abstract are presented below. Further details can be found in the relevant publications.

1. Measurement of the first aerosol indirect effect 
Approximately 6 years (1998-2003) of data have been analyzed. Cases that meet the criteria of being ice-free, single layered, non-precipitating, and free of airborne insects confines analysis to the months of March, April, May, September and October. Cases exhibiting a fairly significant change in aerosol over a period of one day are highlighted here.

Figure 2 shows cloud average $r_{e}$ as a function of aerosol extinction for various narrow LWP bands. IE is defined as the slope:

$$
\mathrm{IE}=-\mathrm{dlnn} r_{\mathrm{e}} / \mathrm{dln} \alpha
$$

And is a measure of the response of the cloud microphysics to changes in aerosol extinction. In the case of Figure 2, tese bands have a $10 \%$ increase in LWP from one to the next to provide reasonable statistics. Over the range $100<\mathrm{LWP}<133 \mathrm{~g} / \mathrm{m} 2$, IE fluctuates between about 0.07 and 0.09 .

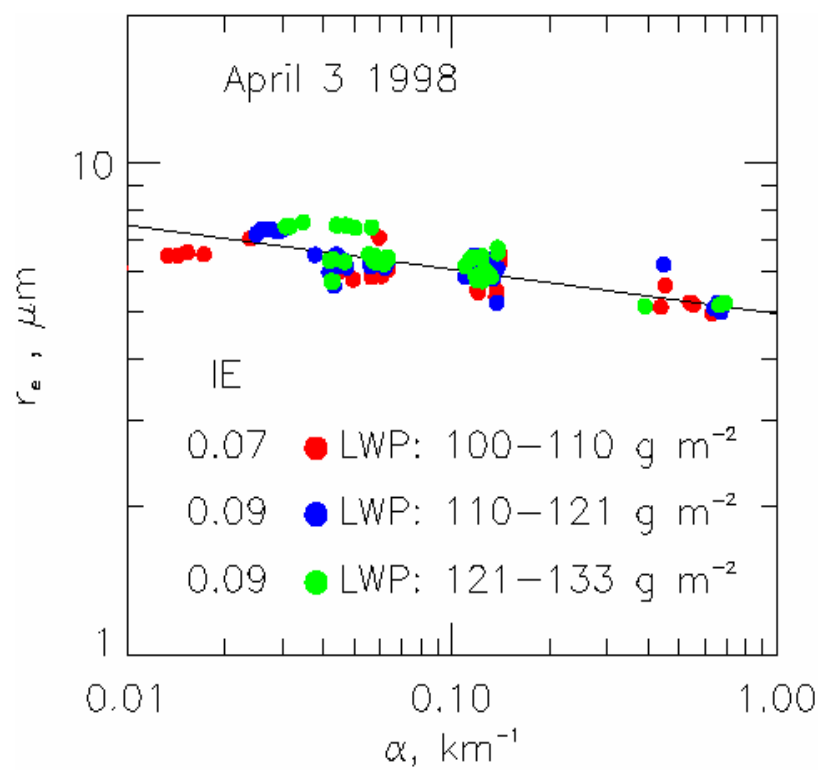

Figure 2: Drop effective radius as a function of aerosol on April 31998 for three different LWP bands. Drop size is retrieved from radar and microwave radiometer. Extinction is measured by the lidar at an altitude of $350 \mathrm{~m}$. (From Feingold et al. 2003)

In comparison, Breon et al., (2002) used the POLarization and Directionality of the Earth Reflectances (POLDER) to quantify the indirect effect on a global scale and found IE 0.04-0.085, i.e., much weaker than that suggested by Twomey or the current work. The reasons for this may be a function of at least two (unmeasured) primary controlling factors: LWP and aerosol composition. Schwartz et al. (2002) have also demonstrated the importance of stratification with respect to LWP.

\section{Dependence on updraft velocity}


Analysis of 7 different events allowed us to calculate the dependence of the mean value of IE on the updraft velocity. Figure 3 suggests a high correlation between the magnitude of the mean IE for a given event and the cloud turbulence. This is in accord with the theory of droplet activation.

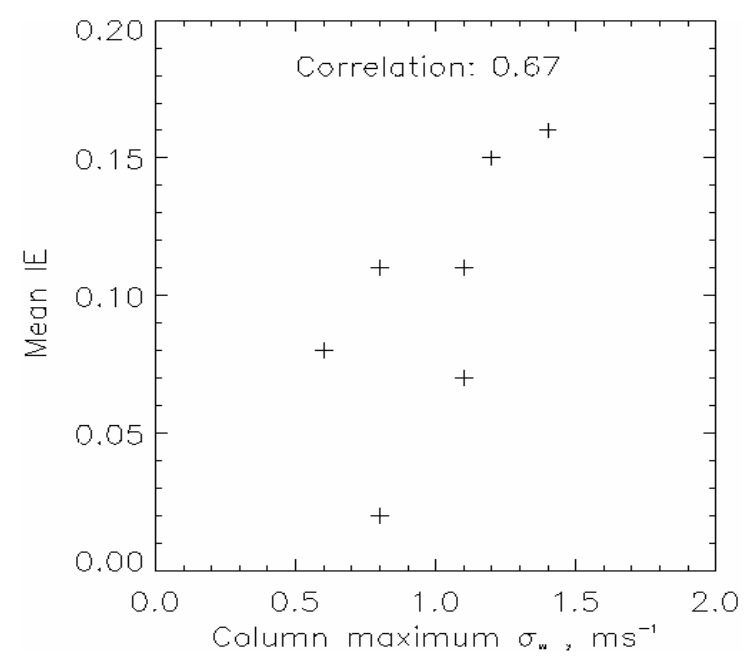

Figure 3: Mean IE as a function of cloud turbulence for 7 different cases. (From Feingold et al. 2003)

\section{Modeling Analysis of Measurement Methodology}

We investigated the extent to which aerosol extinction is a suitable proxy for the aerosol affecting drop formation. First we use multiple realizations of a cloud model to investigate the sensitivity of cloud drop effective radius to aerosol parameters (size distribution and composition) and dynamical parameters (updraft and liquid water content). In general, $\mathrm{r}_{\mathrm{e}}$ is most sensitive to cloud liquid water, a parameter often ignored in indirect effect analyses. The relative importance of the other parameters varies for different conditions but aerosol concentration is consistently important. Updraft plays an increasingly important role under high aerosol loadings. A breakdown of the individual aerosol terms contributing to drop size change shows that use of aerosol extinction as a proxy for size distribution and composition tends to underestimate the magnitude of the first indirect effect. This may influence interpretation of current satellite and surface remote measurements of the indirect effect and explain the low bias in IE measured by satellites

\section{Comparison of 5 different $r_{e}$ retrievals and optimal estimation of the best $r_{e}$ profile}

During May 2003 the Department of Energy's Atmospheric Radiation Measurement Program conducted an Intensive Operations Period (IOP) to measure the 
radiative effects of aerosol and clouds. A suite of both in-situ and remote sensing measurements were available to measure aerosol and cloud parameters.

On May 172003 there was a fortuitous, near-simultaneous sampling of a stratus cloud by five different methods. The retrievals of $r_{e}$ agree with one another to within $20 \backslash \%$, which is approximately the error estimate for most methods. Second, a methodology for deriving a best estimate of $r_{\mathrm{e}}$ from these different instruments, with their different physical properties and sampling volumes, is proposed and applied to the May 17 event. Third, the paper examines the response of $\mathrm{r}_{\mathrm{e}}$ to changes in aerosol on three days during the experiment and examines the consistency of remote sensing and in-situ measurements of the effect of aerosol on $\mathrm{r}_{\mathrm{e}}$. It is shown that in spite of the generally good agreement in derived $r_{e}$, the magnitude of the response of $r_{e}$ to changes in aerosol is quite sensitive to the method of retrieving $r_{e}$, and to the aerosol proxy for cloud condensation nuclei. Nonphysical responses are sometimes noted and it is suggested that further work needs to be done to refine these techniques.

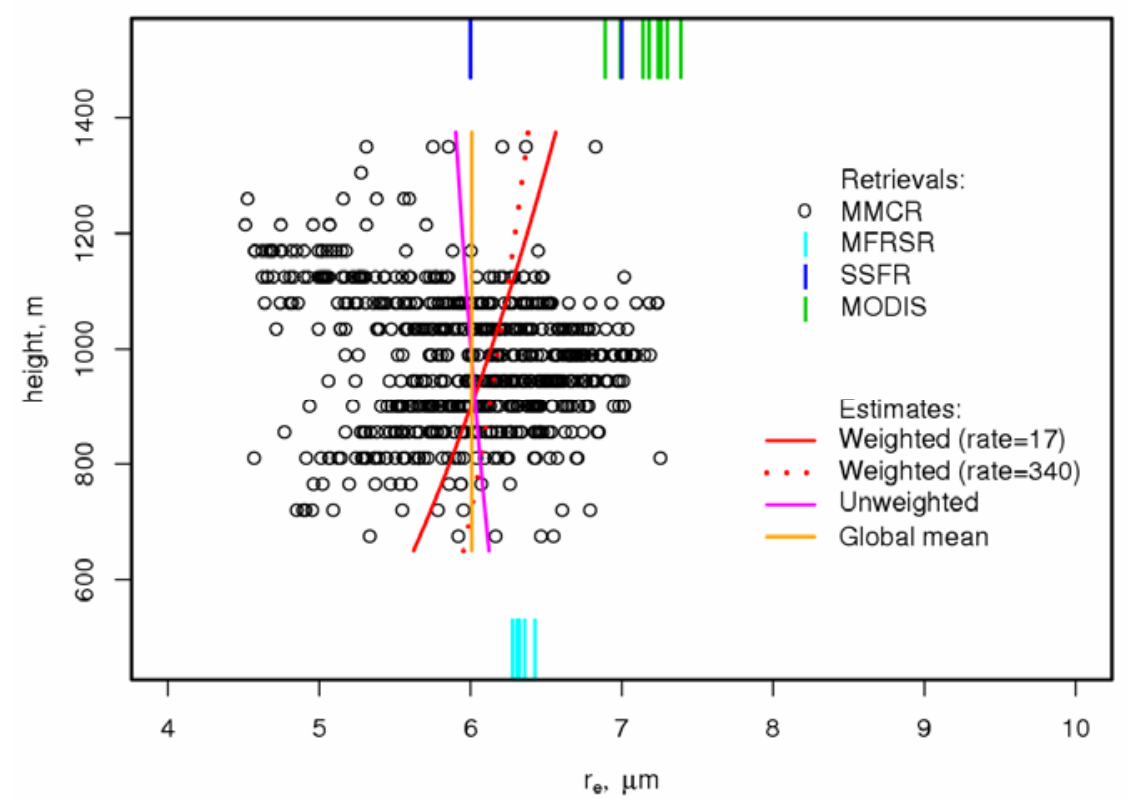

Figure 4: Comparison of 4 different retrievals of drop size based on radar (MMCR), mutifilter rotating shadowband radiometer (MFRSR), Solar Spectral Flux radiometer (SSFR), the satellite based MODIS instrument. The red line represents the best estimate of the retrieval of drop size according to an optimal estimation method. Other line types are as indicated. (From Feingold et al. 2006)

\section{Lidar measurement of Aerosol Hygroscopic Growth}

Aerosol hygroscopicity has a significant effect on radiative properties of aerosols. We applied a lidar method, suitable to cloud-capped, well-mixed atmospheric boundary layers, to determine the hygroscopic growth factor $\mathrm{f}(\mathrm{RH})$ under unperturbed, ambient atmospheric conditions. The data used for the analysis were collected under a wide range of atmospheric aerosol levels during both routine measurement periods and during the intensive operations period (IOP) in May 2003 at the Southern Great Plains 
(SGP) Climate Research Facility in Oklahoma, USA, as part of the Atmospheric Radiation Measurement (ARM) program. We demonstrate for the first time that there is a good correlation $(\sim 0.7)$ between a lidar-derived growth factor (measured over the range $85 \% \mathrm{RH}$ to $96 \% \mathrm{RH}$ ) with a nephelometer-derived growth factor measured over the $\mathrm{RH}$ range $40 \%$ to $85 \%$. For these $\mathrm{RH}$ ranges, the slope of the lidar-derived growth curve is much steeper than that of the nephelometer-derived growth curve, reflecting the rapid increase in particle size with increasing $\mathrm{RH}$. The results are corroborated by aerosol model calculations of lidar backscatter and nephelometer equivalent $\mathrm{f}(\mathrm{RH})$ based on in situ aerosol size and composition measurements during the IOP. It is suggested that the lidar method can provide useful measurements of the dependence of aerosol optical properties on relative humidity, and under conditions closer to saturation than can currently be achieved with humidified nephelometers.

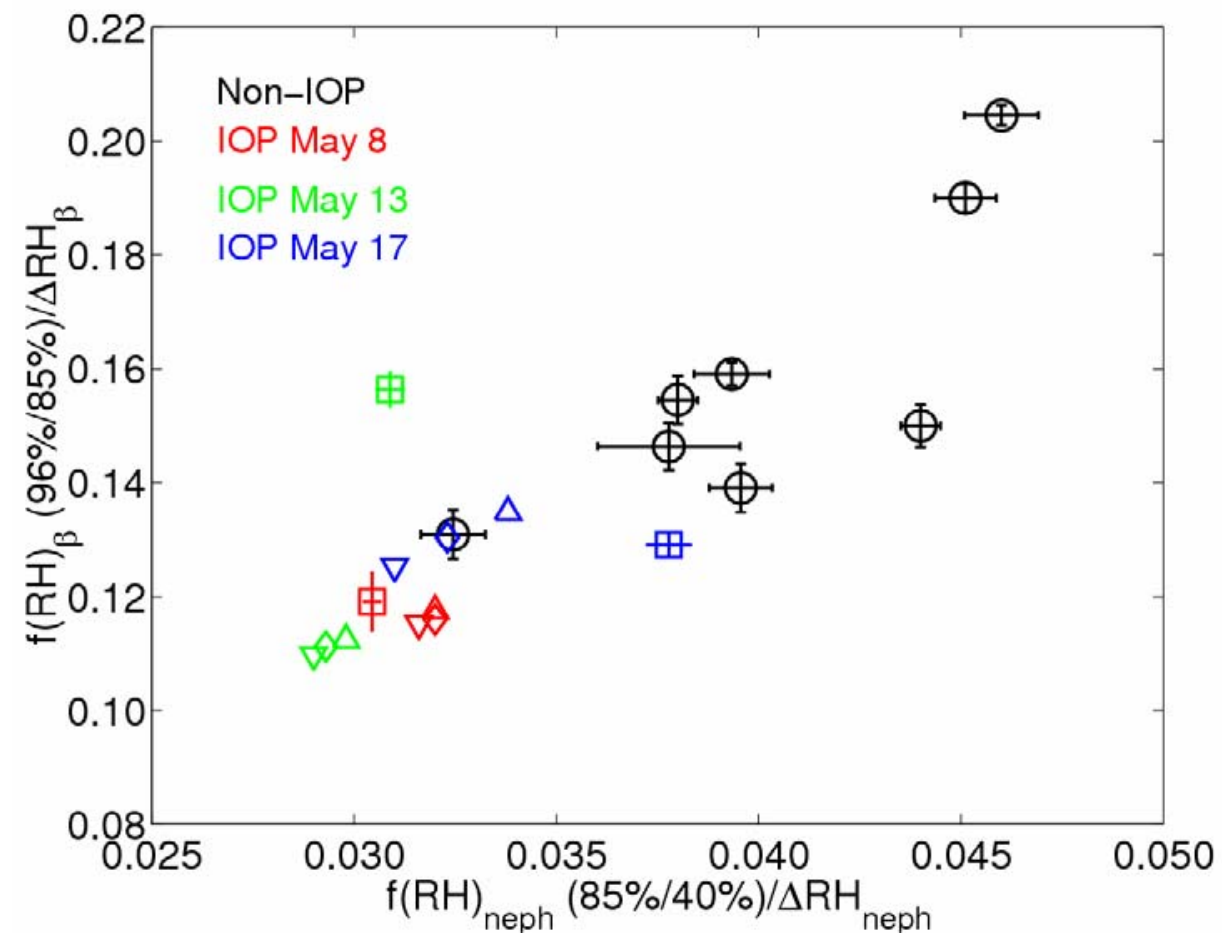

Figure 5: Comparison of the normalized $f(R H)(96 \% / 85 \%) /$ derived from lidar with $f(R H)(85 \% / 40 \%) /$ derived from a nephelometer. Circles denote data obtained during the routine measurement period and square symbols represent data obtained during the IOP (red: May 8; green: May 13; blue: May 17). Error bars denote one standard deviation between the measured $f(R H)$ and the $f(R H)$ determined from the fit parameters..

Additional symbols represent data computed with an aerosol model. Diamonds represent results obtained for mean inorganic fraction.Upward (downward) pointing triangles were obtained for maximum (minimum) inorganic fraction during time period of interest. (From Pahlow et al. 2006) 


\section{Summary}

Our work to date has demonstrated that ground-based remote sensing is a powerful tool for detection and quantification of the indirect effect - defined here in the form originally suggested by Twomey (1977). Although fixed ground-based sites cannot provide global coverage of the indirect effect as satellites do, they can complement the space-based approach by providing longterm data at high temporal resolution. Further gains can be made by placing such instrumentation on moving platforms (e.g., ships). They can also benefit greatly from in-situ intensive measurement campaigns.

Strengths of the method include

1) The effect of aerosol on cloud can be examined in a single column of air at high temporal resolution. The ranging capabilities of a lidar enable one to measure a property of the aerosol that is actually entering the cloud. The ranging capabilities of a radar enable profiling of the drop effective radius. The measurements can easily be placed within the context of macroscale changes in fundamental cloud properties such as liquid water path;

2) cloud processes are addressed at the pertinent scale of cloud formation, i.e., the large eddy scale;

3) Longterm data sets are available for analysis at SGP

Some disadvantages are:

1) Coverage is local rather than regional or global;

2) Success of quantification of the indirect effect depends on the availability of events that have a good range of aerosol amount with little change in aerosol composition. If a variety of events are included to achieve this range, successful quantification depends on an ability to stratify data by aerosol composition and size distribution.

In order to improve the quantification of the indirect effect, it is suggested that data be acquired at a number of choice locations. It is only with the aid of large data sets that we will be able to sort cases by the numerous controlling parameters such as LWP, upstream trajectories, cloud type, etc. In addition, surface measurements of aerosol size distribution and composition should be made, and included in analysis when the surface and cloud layer are coupled.

\section{References}

Albrecht, B.A., 1989: Aerosols, cloud microphysics, and fractional cloudiness, Science, 245, 1227-1230.

Brenguier et al., An overview of the ACE-2 CLOUDYCOLUMN closure experiment, 
Tellus, 52B, 815-827, 2000.

Breon. F.-M., D. Tanre, and S. Generoso, Aerosol effect on cloud droplet size monitored from satellite, Science, 295, 834-838.

Feingold, G., L. A. Remer, J. Ramaprasad, and Y. Kaufman, analysis of smoke impact on clouds in Brazilian biomass burning regions: An extension of Twomey's approach, J. Geophys. Res. 106, 22,907-22,922, 2001.

Feingold, G., W. L. Eberhard. D. E. Veron, and M. Previdi, 2003: First measurements of the Twomey aerosol indirect effect using ground-based remote sensors. Geophys. Res. Lett., 30, No. 6, 1287, doi:10.1029/2002GL016633.

Feingold, G., 2003: Modeling of the first indirect effect: Analysis of measurement requirements. Geophys. Res. Lett., 30, No. 19, 1997, doi:10.1029/2003GL017967.

Feingold, G., R. Furrer, P. Pilewskie, L. A. Remer, Q. Min and H. Jonsson, 2006: Aerosol Indirect Effect Studies at Southern Great Plains during the May 2003 Intensive Operations Period. J. Geophys. Res., 111, D05S14,doi:10.1029/2004JD005648.

Frisch, A. S., C. W. Fairall and J. B. Snider, On the measurement of stratus cloud and drizzle parameters with a K- band Doppler radar and a microwave radiometer, J. Atmos. Sci.., 52, 2788-2799, 1995.

Han, Q., W. B. Rossow, J. Chou, and R. M. Welch, Global survey of ther relationships of cloud albedo and liquid water path with droplet size using ISCCP.

J. Climate, 7, 1516-1528, 1998.

Kaufman, Y. J., and T. Nakajima, Effect of Amazon smoke on cloud microphysics and albedo - analysis from satellite imagery, J. Appl. Meteor., 32, 729-744, 1993.

McFarlane, S. A., K. F. Evans, and A. S. Ackerman, A Bayesian algorithm for the retrieval of liquid water cloud properties from microwave radiometer and millimeter radar data, J. Geophys. Res., submitted, 2002.

Nakajima, T., A. Higurashi, K. Kawamoto, and J. E. Penner, A possible correlation between satellite-derived cloud and aerosol microphysical parameters, Geophys. res. Lett., 28 p. 1171., 2001.

Pahlow, M., G. Feingold, A. Jefferson, E. Andrews, J. A. Ogren, J. Wang, Y.-N. Lee, R. A. Ferrare,and D. D. Turner, 2006: Comparison between lidar and nephelometer measurements of aerosol hygroscopicity at the Southern Great Plains Atmospheric Radiation Measurement site. J. Geophys. Res., 111, D05S15,doi:10.1029/2004JD005646.

Rosenfeld, D., Suppression of rain and snow by urban and industrial air pollution. Science, 287, 1793-1796, 2000. 
Stephens, G. L., Radiation profiles in extended water clouds. I: Theory. J. Atmos. Sci.., 35, 2111-2122, 1978.

Twomey, S., The influence of pollution on the short wave albedo of clouds, J. Atmos. Sci., 34, 1149-1152, 1977.

Wetzel, M.A., and L.L. Stowe, Satellite-observed patterns in stratus cloud microphysics, aerosol optical thickness, and shortwave radiative forcing. J. Geophys. Res., 104, 31,287-31,299, 1999. 